\title{
Alguns textos Paulinos à luz de Qumran
}

\author{
Florentino García Martínez. K.U. Leuven
}

O último volume, que apareceu na Série de Brill, de Estudos Paulinos, editado por Stanley Porter, traz um título que expressa a tríplice identidade do Apóstolo Paulo: Judeu, Grego e Romano ${ }^{1}$. O Professor Isidoro Mazzarolo, quando me convidou para participar neste Simpósio, delimitou que eu deveria tratar sobre a primeira identidade de Paulo, sua identidade Judaica. Sobre esta identidade, não existe alguma dúvida, visto que, repetidamente, o próprio Paulo a proclama. Assim, em Gl 1,14, ele nos assegura que, seu desejo de exterminar a Igreja de Deus, estava motivado pelo "seu zelo pelas tradições paternas." E, em 2Cor 11,22, numa série de perguntas, altamente retóricas, Paulo, falando de seus opositores, diz: "São hebreus? Também eu. São israelitas? Também eu. São descendentes de Abraão? Também eu." E, em Fl 3,5-6, ele traça-nos a sua genealogia: "circuncidado ao oitavo dia, da raça de Israel, da tribo de Benjamim, hebreu, filho de hebreus; quanto à Lei, fariseu; quanto ao zelo, perseguidor da Igreja; quanto à justiça, que há na Lei, irrepreensível.” A identidade judaica de Paulo de Tarso é, portanto, totalmente clara, sem a necessidade de recorrer às informações que nos proporciona o livro dos Atos dos Apóstolos.

Esta identidade judaica tem sido muito estudada nos últimos anos, desde do ponto de vista cristão, e, sobretudo, a partir do livro de E. P. Sanders ${ }^{2}$, Paulo e o Judaismo Palestinense, que supõe uma verdadeira revolução no modo de compre-

\footnotetext{
* Tradução de Leonardo Agostini Fernandes, Dept ${ }^{\circ}$. Teologia PUC-RIO.

${ }^{1}$ S.E. Porter (ed.), Paul: Jew, Greek, and Roman (Pauline Studies 6; Leiden, 2009).

${ }^{2}$ E. P. Sanders, Paul and Palestinian Judaism: A Comparison of Patterns of Religion (Philadelphia, 1977), e sua obra posterior Paul, the Law, and the Jewish People (Philadelphia, 1983).
} 
ender o sistema teológico do Apóstolo ${ }^{3}$. Esta revolução continua e tem sido corrigida nos numerosos escritos de James D. G. Dunn, que culminam nos seus livros Jesus, Paulo e a Lei, de 1990, e Teologia do Apóstolo Paulo, de $1998,{ }^{4}$ bem como nas discussões em torno do que Dunn designa como a "new perspective on Paul." Também no mundo judaico, a figura de Paulo tem sido objeto de um renovado interesse, por exemplo, nos livros de Alan Segal, ${ }^{6}$ de Daniel Boyarin ${ }^{7}$, e em muitos outros. Eu não vou entrar nestas discussões, que, certamente, são muito importantes e requerem competências que eu não disponho. Minha especialidade é mais reduzida, embora, ainda sendo o editor do Journal for the Study of Judaism in the Persian, Hellenistic, and Roman Peri$o d$, a maior parte, de minha atividade acadêmica, concentra-se no estudo dos manuscritos do Mar Morto.

Esta limitação da minha especialidade não é, na realidade, demasiada grave neste caso, porque um simples olhar sobre os materiais coletados para o projeto da Academia de Língua Hebraica de Israel, de elaborar um "Dicionário Histórico da Língua Hebraica", prova que a quase totalidade do nosso conhecimento da literatura Judaica, escrita em Hebraico ou Aramaico, anterior a Paulo de Tarso, nos foi proporcionada, exclusivamente, pelas descobertas do Mar Morto. E as mudanças no estudo da teologia de São Paulo têm sido motivadas, em grande parte, pela publicação dos manuscritos de Qumran, apesar destes textos terem sido escritos,

\footnotetext{
${ }^{3}$ O posicionamento, obviamente, de Sanders tem sido combatido por outros investigadores. Ver, por exemplo, M. Hengel - R. Deines, "E. P Sanders' 'Common Judaism, ' Jesus and the Pharisees," JTS 46 (1995): 1-70, y D. A. Carson, P. T. O'Brien and M. Seifrid (eds), Justification and Variegated Nomism. Volume 1: The Complexities of Second Temple Judaism; Volume 2: The Paradoxes of Paul (Grand Rapids, 2001, 2004).

${ }^{4}$ J. D. G. Dunn, Jesus, Paul and the Law: Studies in Mark and Galatians (London, 1990) y The Theology of Paul the Apostle (Grand Rapids, 1998).

5 J. D. G. Dunn, "The New Perspective on Paul," Bulletin of the John Rylands Library 65 (1983): 95-122, sua recente coleção de artigos sobre o tema, The New Perspective on Paul (Grand Rapids, 2007) e a ampla bibliografía existente na página web "The Paul Page dedicated to the New Perspective on Paul" http://www.thepaulpage.com/

${ }^{6}$ A. Segal, Paul the Convert: The Apostolate and Apostasy of Saul the Pharisee (New Haven, 1990).

${ }^{7}$ D. Boyarin, A Radical Jew: Paul and the Politics of Identity (Berkeley, 1994).

${ }^{8}$ Como prova uma verificação nas bibliografias publicadas nos dois volumes que me foram dedicados, devido a minha jubilação em Groningen e em Leuven, A. Hilhorst, E. Puech, E. Tigchelaar (eds.), Flores Florentino. Dead Sea Scrolls and Other Early Jewish Studies in Honour of Florentino Garcia Martínez (JSJSup 122; Leiden, 2007) 803-816, e H. Ausloos, B. Lemmelijn, M. Vervenne, Florilegium Lovaniense: Studies in Septuagint and Textual Criticism in Honour of Florentino Garcia Martínez (BETL 224; Leuven, 2008) 13-33.

${ }^{9}$ Publicados em microfichas, Materials for the Dictionary. Series I: 200 B.C.E. - 300 C.E. (Jerusalém, 1998).
} 
na sua grande maioria, em hebraico ou aramaico ${ }^{10}$, o que dificulta a comparação com o grego das cartas paulinas. Esta diferença lingüística, entre os dois grupos de escritos, dos quais nos ocuparemos, é preciso tê-la bem presente, para relativizar a certeza das conclusões que podemos chegar. Ao lado disto, é preciso ter bem presente a incerteza da atribuição a Paulo da autoria de várias das cartas paulinas e até a possibilidade de interpolações dentro de algumas delas. Por isso, nesta conferência, me limitarei aos materiais autênticos de Paulo, quer dizer, às sete cartas reconhecidas, geralmente, como paulinas (1Tessalonicenses, 12Coríntios, Gálatas, Romanos, Filipenses e Filemon), sem recorrer às outras seis cartas (Colossenses, Efésios, 2Tesalonicenses, 1-2Timoteo, Tito) classificadas, geralmente, como deutero-paulinas. ${ }^{11}$ Pelo mesmo motivo, não irei considerar alguns textos, como 2Corintios 6,14-7,1 (uma unidade autônoma, que interrompe, claramente, o desenvolvimento onde o texto está inserido, e que está repleto de palavras únicas no Novo Testamento), que, nos estudos sobre Paulo e Qumran, é considerado como o melhor exemplo das relações entre os dois grupos de escritos ${ }^{12}$, porém, muitos investigadores consideram como interpolado na carta de Paulo ${ }^{13}$.

\footnotetext{
${ }^{10}$ Com a exceção de alguns poucos fragmentos de manuscritos bíblicos em grego, procedentes de Qumran. Nas outras coleções, a presença de textos documentados em grego é mais abundante, veja-se os índices de textos gregos (tanto literários como documentários) de E. Tov em E. Tov et alii. (eds.), The Texts from the Judaean Desert: Indices and Introduction to the Discoveries in the Judaean Desert Series (DJD 39; Oxford, 2002), 215-220.

${ }^{11}$ Seguindo a opinião comum dos especialistas do Novo Testamento. Ver, por exemplo, as introduções de U. Schnelle, Einleitung in das Neu Testament (UTB 1830; Göttingen, 1996), H. Conzelman A. Lindemann, arbeitsbuch zum Neuen Testament (UTB 52; Tübingen, 2000), B.D. Ehrman, The New Testament. A Historical Introduction to the Early Christian Writings (Oxford, 2000).

${ }_{12}$ Por exemplo, P. Benoit, no seu artigo, "Qumran and the New Testament," em J. Murphy O'Connor - J.H. Charlesworth (eds.), Paul and the Dead Sea Scrolls, (New York, 1990), 5, afirma: "It must suffice here to evoke one passage, 2 Cor 6:14-7:1, which is Qumranian in both though and style; a meteor fallen from the heaven of Qumran into Paul's epistle," o H.W. Kuhn, "The Impact of the Qumran Scrolls on the Understanding of Paul," em D. Dimant - U. Rappaport (eds.), The Dead Sea Scrolls Forty Years of Research (STDJ 10; Leiden, 1992), 337 que enumera "the 'Top Ten' passages in the seven authentic letters of Paul on which the Qumran Scrolls throw light (apart from the closest parallel 2 Cor 6:14-7:1)."

${ }^{13}$ Entre aqueles que consideram a passagem uma interpolação, ver J.A. Fitzmyer, "Qumran and the Interpolated Fragment in 2Cor 6:14-7:1," CBQ 23 (1961), 271-280, reimpresso em Essays on the Semitic Background of the New Testament (Sources for Biblical Study 5; London , 1974), 205-217; J. Gnilka, "2Cor 6:14-7:1 in the Light of the Qumran Texts and the Testaments of the Twelve Patriarchs," em Paul and the Dead Sea Scrolls, 66; H.D. Betz, “2Cor 6:14-7:1: An Anti-Pauline Fragment?" JBL 92 (1973): 88-108. Entre os defensores da origem paulina, ver J. Lambrecht, "The Fragment 2 Corinthians 6,14-7,1: A Plea for Its Authenticity," em R. Bieringer - J. Lambrecht, Studies in 2 Corinthians (BETL 112; Leuven, 1994), 531-549 y R. Bieringen , "2 Korinther 6,14-7,1 im Kontexts des 2. Korintherbriefes. Forschubgsüberblick und Versuch eines eigen Zugangs," in idem, 551-570. Para uma bibliografia
} 
Dentro destes limites, que eu mesmo me impus, vou tentar apresentarlhes a maneira em que os textos de Qumran iluminam, para nós, alguns elementos dos escritos paulinos. Iniciarei por um par de exemplos, onde a linguagem e a terminologia, empregadas por Paulo, são esclarecidas por determinadas frases dos manuscritos. Do nível da linguagem passarei para o nível da teologia do Apóstolo, se é que podemos distinguir esta teologia da linguagem com a qual ele se expressa. Terminarei aludindo ao uso que Paulo faz das Escrituras, visto que, como lhes direi, com mais detalhes, na conferência de conclusão, foi precisamente o recurso à fonte comum, a Bíblia Hebraica, o que nos permitiu compreender as relações entre os textos de Qumran e o Novo Testamento em geral (e, portanto, também, entre Qumran e São Paulo) sem a necessidade de recorrer a uma improvável relação genética ou de dependência literária entre os dois escritos. Espero que minha apresentação seja simples e compreensível, porém não se deve esquecer o que nos diz a Segunda carta de Pedro, quando fala: "conforme também o nosso amado irmão Paulo vos escreveu, segundo a sabedoria que the foi dada", esclarecendo que: "em todas as suas cartas, ao falar nelas desse tema, se encontram alguns pontos difíceis de entender, que os ignorantes e vacilantes torcem, como fazem com as demais Escrituras, para a sua própria perdição." $(2 \mathrm{Pd} 3,15-16)$.

\section{Obras da lei}

Começo com uma famosa frase de Paulo, que, até pouco tempo, não conhecíamos nenhum paralelo exato em Hebraico ou em Aramaico. Refiro-

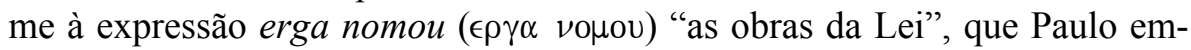
prega, repetidamente, nas cartas aos Gálatas e aos Romanos (Gl 2,16,

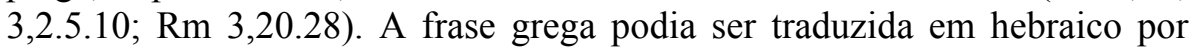
ma 'aśe torah (מעשי תורה), visto que a LXX traduz "obra" na maioria dos casos por תורה e "lei" e, disto, a tradução tradicional hebraica do Novo Testamento empregava a frase ma 'aśe torah para traduzir a expressão paulina. Todavia, como lhes dizia, a frase não estava testemunhada em hebraico, com exceção de um caso de leitura incerta em $4 \mathrm{Q} 174,{ }^{14}$ antes da publicação em 1994 de 4QMMT, uma obra conservada, parcialmente, em seis

completa do fragmento paulino, ver R. Bieringer, E. Nathan, D. Kurek-Chomycz, 2 Corinthians: A Bibliography (Biblical Tools and Studies 5; Leuven, 2008), 94-100.

${ }^{14} \mathrm{O}$ editor J.M. Allegro lê a frase en 4Q174 1-2 i 7 (DJD V, 33), porém, a leitura foi posta em dúvida por J. Strugnell en RevQ 7 (1967-69): 123, corrigida por G. Brooke (Exegesis at Qumran: 4QFlorilegium in its Jewish Context, 108), e descartada, definitvamente, pela análise paleográfica de Puech (La croyance des Esséniens en la vie future, 2: 578) y de Kuhn ("Die Bedeutung der Qumrantexte für das Verständnis des Galatatterbriefes aus den Münchener Projekt: Qumran und das Neue Testament," in New Qumran Texts and Studies, 205). 
manuscritos, 4Q394-398, todos eles provenientes da Gruta 4. A frase aparece na exortação final (C 27) ${ }^{15}$, o epílogo da composição, e foi empregada para dar o título com o que se conhece esta composição: Miqșat ma 'aśe hatorah "Algumas das obras da lei." ${ }^{16}$ Evidentemente, enquanto o texto foi publicado, sua importância para compreender a utilização da frase paulina foi evidente e vem, repetidamente, sendo estudado, mesmo se os investigadores chegam a conclusões muito diversas. ${ }^{17}$ Minha interpretação apóia-se no significado que a frase tem em 4QMMT, quando este documento é lido dentro do contexto qumrânico. ${ }^{18}$

Pelo que se pode concluir, do conteúdo da composição qumrânica recuperado, trata-se de um tratado sistemático das disputas legais, por causa das quais um grupo de "Sadocitas" se separou de outro grupo que segue uma prática distinta, que a tradição rabínica, posterior, designará como "farisaica". E, pelo que se pode concluir das características formais da obra, trata-se de um código legal que se conclui (como é o caso do livro bíblico do Deuterônomio) com uma exortação à observância destas leis. Por esta conclusão, em que a frase, "obras da lei", está empregada, proporciona-nos a expressa afirmação de que a ruptura do grupo foi motivada pela fidelidade a esta interpretação concreta das obras da lei ("nos temos separado da maioria do povo"), e, ao mesmo tempo, leva-nos a outro dado fundamental para compreender a ruptura do grupo que a escreve. No fundo, é uma exortação ao estudo da Bíblia (em todas as suas partes: "os livros de Moisés, as palavras dos Profetas e de Davi"), para chegar a descobrir nela, que a interpretação dos aspectos legais, de que trata a primeira parte do documento, oferecida pelo grupo, é a única interpretação correta. Ainda que esta interpretação não se limite aos aspectos legais, senão que compreende todo o devir da história do povo, porque alude às bênçãos e maldições ocorridas ao longo da história. Graças a esta interpretação, o grupo, que escreve o documen-

\footnotetext{
${ }^{15}$ Na nomenclatura da edição de E. Qimron - J. Strugnell, Qumran Cave 4.V: Miqșat ma 'aśe hatorah (DJD X; Oxford, 1994), 62. Se trata del manuscrito 4Q398 14-17 3.

${ }^{16} \mathrm{O}$ estudo mais recente do epílogo desta obra é o de H. Von Weissenberg, 4QMMT: Reevaluating the Text, the Function, and the Meaning of the Epilogue (STDJ 82; Leiden, 2009).

${ }^{17}$ Como exemplos das distintas posições, ver J. Dunn, "4QMMT and Galatians," NTS 43 (1997): 147-153 y "Noch eimal 'Works of the Law': The Dialogue Continues," en I. Dunderberg - C. Tuckett (eds.), Fair Play: Diversity and Conflicts in Early Christianity (Leiden, 2002), 273-290; M. G. Abegg, "4QMMT C27, 31 and 'Works of Righteousness," DSD 6 (1999): 139-147 y "4QMMT, Paul, and 'Works of the Law'," em P. Flint (ed.), The Bible at Qumran: Text, Shape, and Interpretation (Grand Rapids, 2001), 203-216; M. Bachmann, "Rechtfertigung und Gestzeswerke bei Paulus," TZ 49 (1993): 1-33 y "4QMMT und Galaterbrief, ma 'aśe hatorah und ERGA NOMOU," ZNW 89 (1998): 91-113.

${ }^{18}$ F. García Martínez, "4QMMT in a Qumran Context," en J. Kampen - M. Bernstein (eds.), Reading 4QMMT. New Perspectives on Qumran Law and History (SBL Symposium Series 2; Atlanta, 1996), 15-27, particularmente as páginas, 23-26.
} 
to, pôde descobrir que já se cumpriram as bênçãos e as maldições anunciadas no texto bíblico, e que, agora, está vivendo o "final dos tempos". A passagem, em questão, é a conclusão da obra, conservada, integralmente, em 4Q398 e, parcialmente, em 4Q399, podendo ser traduzida da seguinte maneira:

E também nós te escrevemos algumas das obras da Torah que pensamos boas para ti e para teu povo, pois [vimos] em ti inteligência e conhecimento da Torah. Considera todas estas coisas e busca diante dele que ele confirme o teu conselho e afaste de ti a maquinação malvada e o conselho de Belial de maneira que possas alegrar-te no final do tempo no descobrimento de que algumas de nossas palavras são verdadeiras. E te será contado em justiça, quando fizeres o que é reto e bom diante dele, para teu bem e o bem de Israel. ${ }^{19}$ (4Q398 2 ii 2-8)

Estas "obras da lei", às quais o texto se refere, são as interpretações discutidas na primeira parte da composição. Das que se conservaram, temos os restos de umas vinte. Dizem respeito a normas destinadas a proteger a pureza ritual dos sacerdotes, do povo, em geral, e, inclusive, da cidade de Jerusalém, bem como elementos do culto sacrifical, do templo e dos sacerdotes em geral. A interpretação correta destas normas é considerada muito importante para justificar porque o grupo, que redigiu o documento, se separou do resto do povo, que não aceita a interpretação que ele propõe. Ao destinatário, considerado um especialista na lei, exorta-se a estudá-las para compreender que elas são verdadeiras e a observálas, que é o que garante a salvação divina. Fica claro que, no documento, as "obras da lei", não são só consideradas muito positivamente, mais que, o seu cumprimento é a condição imprescindível para obter a salvação.

No primeiro uso paulino da frase, em Gl 2,16 (local onde a expressão aparece três vezes), Paulo diz:

Sabendo que [o] homem não fica justificado por [pelas] obras de [da] lei, senão mediante a fé em Cristo Jesus, também nós abraçamos a fé em Cristo Jesus, para alcançar a justificação por [pela] fé em Cristo e não por [pelas] obras da lei; porque por [pelas] obras de [da] lei nenhum

\footnotetext{
19 Tradução de F. García Martínez, Textos de Qumrán (Madrid, 2000), 135-136 [trad. em português, Textos de Qumran, Vozes, 1995], que segue a edição de F. Garía Martínez - E.J. Tigchelaar, The Dead Sea Scrolls: Study Edition (=DSSSE) (Leiden-Gran Rapids, 2000) 2: 802. Onde a tradução em português colocou "preceitos da Torá" (Textos de Qumran, p. 127), mantive "obras da Torah", conforme o original do autor (nota do tradutor).
} 
vivente (lit. pasa sarx, "toda carne”) será declarado justo $^{20}$.

O pensamento de Paulo é totalmente claro: é a fé em Cristo a que justifica e não as obras da lei. Todavia, que Paulo deseja dizer, exatamente, quando fala de "as obras da lei?". O significado preciso, da frase de Paulo, era muito discutido, antes de acontecer a descoberta do texto qumrânico, e continuou sendo discutido, depois da sua publicação. ${ }^{21}$ Levando-se em conta, porém, o contexto no qual a frase está empregada pela primeira vez, quer dizer, depois da referência aos conflitos que Paulo acaba de aludir, o incidente de Jerusalém (em G1 2,2-4, o problema da circuncisão) e o incidente de Antioquia (em Gl 2,11-14, o problema das leis alimentares), fica evidente que Paulo usa a frase para referir-se às práticas que Pedro e os outros judeus observantes consideram tão importantes, a ponto de obrigá-los a se separar dos outros crentes em Jesus, que dão menos importância, sejam cristãos provenientes do mundo pagão, incircuncisos, ou procedentes do judaísmo, que, porém, tenham abandonado as normas alimentares, como o mesmo Pedro, antes de mudar de opinião. Isto quer dizer que Paulo, como os autores 4QMMT, por "obras da lei", entende as práticas concretas, cuja importância é tal que, sua observância leva, aos que as cumprem, a se separarem dos que não as cumprem ou as interpretam de outro modo. No texto qumrânico, a observância destas obras da lei é a que leva à salvação. Paulo afirma, exatamente, o contrário: é a fé em Cristo que salva e não a observância das "obras da lei". Eu não creio, porém, que possa haver alguma dúvida, de que o texto qumrânico esclarece o que o judeu Paulo entende por "obras da lei" e, deste modo, nos ajuda a compreender melhor o texto do Apóstolo.

\footnotetext{
${ }^{20}$ Os textos bíblicos citados seguem a Bíblia de Jerusalém, nova edição, revista e ampliada (2002). Em alguns casos, como este, sigo uma tradução literal da versão feita pelo autor.

${ }^{21}$ Ver as monografías de R.K. Rapa, The meaning of "works of the law" in Galatians and Romans (Studies in Biblical Literature 31; New York, 2001) e de Ch. A. Amadi-Azuogu, Paul and the law in the arguments of Galatians: a rhetorical and exegetical analysis of Galatians 2,14-6,2 (Bonner biblische Beiträge 104; Weinheim 1996). Entre as publicações mais recentes, se observa uma grande variedade de opiniões. Ver, por exemplo, J.K. Hardin, Galatians and the imperial cult (WUZN 2.R 237; Tübingen, 2008); M. Hietanen, Paul's argumentation in Galatians ( Library of New Testament studies 344; London, 2007); A. du Toit, Andrie, C. Breytenbach, D.S. du Toit, Focusing on Paul : Persuasion and Theological Design in Romans and Galatians (BZNW 151 ; Berlin, 2007); P.Ch. Onwuka, The law, redemption and freedom in Christ: An exegetical-theological Study of Galatian 3,10-14 and Romans 7,16 (Roma,2007); T.A. Wilson, The curse of the law and the crisis in Galatia: Reassessing the Purpose of Galatians (WUNT 2.R: 225; Tübingen, 2007).
} 


\section{A maldição da lei}

Um pouco mais adiante, na mesma carta aos Gálatas, Paulo cita um texto do Deuteronômio, como prova de que Cristo nos redimiu mediante sua crucifixão, que faz dele um maldito:

Cristo nos resgatou da maldição da lei, tornando-se, por nós, em [objeto de] maldição, porque está escrito: "maldito todo o que for colocado num madeiro." (Gl 3,13).

Paulo prova o seu ponto de vista com a citação de Deuteronômio "maldito todo o que for colocado num madeiro." 22 Os comentários da carta paulina tinham dificuldade em compreender o dado apropriado da citação, dentro do argumento de Paulo, visto que o texto bíblico trata, em particular, de um executado, que, depois de morto, deverá ser tido por um opróbrio, ainda que não passe a noite dependurado para não contaminar a terra. $\mathrm{O}$ texto do deuteronômio diz:

"Se um homem, culpado de um crime que merece a pena de morte, é morto e suspenso a uma árvore, seu cadáver não poderá permanecer na árvore à noite; tu o sepultarás no mesmo dia, pois o que for suspenso é um maldito de Deus. Deste modo não tornarás impuro o solo que Iahweh teu Deus te dará como herança." (Dt 21,22-23).

O texto bíblico, como se pode comprovar pelos comentários ${ }^{23}$, é interpretado, geralmente, no sentido da tradução grega dos LXX, onde está mais claro que no TM, de que se trata da exposição de um executado ao opróbrio, ao ser colocado num madeiro e não tem nada a ver com a crucifixão ${ }^{24}$. Disto, a crucifixão não figura entre os quatro modos tradicionais usados no judaísmo executar a pena capital (apedrejando, queimando, decapitando e estrangulando ${ }^{25}$, e pensava-se, geralmente, que a crucifixão era uma punição característi-

\footnotetext{
${ }^{22}$ Ver, por exemplo, A. Caneday, "'Redeemed from the Curse of the Law': The Use of Deut 21:22-23 in Gal 3:13," TrinJ 10 (1989): 185-209.

${ }^{23}$ Ver por exemplo, E. Nilsen, Deuteronomium (Handbuch zum Alten Testament 1/6; Tübingen, 1995); R.D. Nelson, Deuteronomy: a commentary (The Old Testament library; Louisville, 2002); U. Rüterswörden, Das Buch Deuteronomium (Neuer Stuttgarter Kommentar. Altes Testament 4; Stuttgart, 2006).

${ }^{24}$ Ver o comentário de C. Doignez y M. Harl, en La Bible d'Alexandrie: 5 Le Deutéronome (Paris, 1992), 248-249.

${ }^{25}$ M. Hengel, Crucifixion in the Ancient World and the Folly of the Message of the Cross (Philadelphia, 1977); J.A. Fitzmyer, "Crucifixion in Ancient Palestina, Qumran Literature, and the New Testament," CBQ 20 (1978): 493-513.
} 
ca, muito em voga entre os romanos, porém, totalmente alheia ao mundo judaico. A referência paulina resultava incompreensível, até que um fragmento do Rolo do Templo (1Q19) veio comprovar que o texto do Deuteronômio tinha sido interpretado, em determinadas correntes judaicas, como uma alusão à crucifixão, e outro texto qumrânico, o pesher de Naum, provou, sem dúvida alguma, que a crucifixão era praticada em ambiente judaico, muito antes da chegada dos romanos.

O fragmento em questão, Rolo do Templo, veio ao público por obra de Yadin $^{26}$, antes da edição completa do manuscrito e, mesmo que sua interpretação tenha sido contestada, diretamente, por outros investigadores ${ }^{27}$, a publicação do manuscrito deixou claro que o texto qumrânico considerava a crucifixão como uma das formas possíveis de se executar a pena capital, e que esta antiga interpretação do texto bíblico era, portanto, totalmente diferente do que será a interpretação rabínica posterior ${ }^{28}$. O Rolo do Templo que cita, sem dúvida alguma, o mesmo texto do Deuteronômio, citado por Paulo, inverte a ordem dos verbos empregados (primeiro suspende-se o réu, que logo morre), designando, assim, que não se trata da exposição de alguém previamente executado para seu opróbrio, e aplica esta pena da crucifixão a dois crimes concretos: traição e passagem para o lado inimigo. ${ }^{29}$

Se houver um espia contra seu povo, que entrega seu povo a uma nação estrangeira ou faz o mal contra seu povo, o suspenderás a uma árvore e morrerá. Pelo testemunho de duas testemunhas e pelo testemunho de três testemunhas será executado e o suspenderão à árvore. Se houver em um homem um pecado condenável à morte $\mathrm{e}$ escapa em meio das nações e maldiz o seu povo e os filhos de Israel, também a ele o suspendereis à árvore e morrerá. Seus cadáveres não passarão a noite na árvore, mas os enterrareis durante este dia, porque são malditos

\footnotetext{
${ }^{26}$ Num artigo, no qual comentava, precisamente, o texto do pesher de Naum, Y. Yadin, "Pesher Nahum (4QpNuhum) Reconsidered," IEJ 21 (1971): 1-13.

${ }^{27}$ J.M. Baumgarten, "Does TLH in the Temple Scroll Refer to Crucifixion?" JBL 91 (1972): 215-225; "Hanging and Treason in Qumran and Roman Law," Eretz Israel 16 (1982): 7-16. D.J. Halperin, "Crucifixion, the Nahum Pesher, and the Rabbinic Penalty of Strangulation," JJS 32 (1981): 32-46.

${ }_{28}$ Ver M. Bernstein, "KY QLLT 'LHYM TLWY (Deut 21:23): A Study in Early Jewish Exegesis," JQR 74 (1983): 21-45.

${ }^{29}$ Texto hebraico em Y. Yadin, Megillat ham-Miqdaš - The Temple Scroll (Jerusalem 1977). Para ediciones algo distintas, ver E. Qimron, The Temple Scroll: A Critical Edition with Extensive Reconstructions (Judean Desert Studies; Beer-Sheva - Jerusalem 1996); DSSSE 2: 1228-1289 y A. Steudel, Die Texte aus Qumran II (Darmstadt 2001).
} 
por Deus e pelos homens os suspensos à árvore; assim não contaminareis a terra que eu te dou em herança. $(11 \mathrm{Q} 1964: 7-13)^{30}$

O texto não foi conservado na outra cópia do Rolo do Templo da Gruta 11 $(11 \mathrm{Q} 20)^{31}$, mas sim, parcialmente, na cópia da Gruta 4 (4Q524 14), ainda que sem a citação conclusiva de Dt $21,23 .^{32}$ A evidência proporcionada por este texto, quanto ao uso do Deuteronômio para designar a crucifixão, é clara, mesmo não podendo considerá-la conclusiva, porque, junto aos usos encontrados no texto qumrânico, muda-se a ordem dos verbos do texto bíblico (suspender à árvore e morrer), indicando de que se trata, precisamente, de crucifixão e não de suspender o cadáver por opróbrio. Na cópia da Gruta 4, encontramos outra referência (na adição sobre os textos das três testemunhas), na qual a ordem é a do texto bíblico: primeiro se executa o réu e logo se suspende à árvore.

A prova, totalmente conclusiva, de que a crucifixão era utilizada na Judéia, muito antes da cegada dos romanos, nos é proporcionada pelo outro texto que mencionei, um comentário ao Profeta Naum, e que não deixa lugar para alguma dúvida, visto que a expressão ali utilizada é a de suspender homens vivos na árvore (יתלה אנשים חיים), que só pode referir-se à crucifixão.

E o que diz $(\mathrm{Na} 2,13)$ ["enche de presas a sua cova e sua guarida de despojos" Sua interpretação se refere ao Leão Furioso [que encheu a sua guarida com uma multidão de cadáveres, executando vin]ganças contra os que buscam interpretações fáceis, que dependurou homens vivos [na árvore, cometendo uma abominação que não se cometia] em Israel desde antigamente, pois é terrível para o dependurado vivo na árvore. (4Q169 3-4 i 6-8) $)^{33}$

O texto nos foi divulgado por J. M. Allegro em $1956^{34}$, e, desde então, tem sido objeto de numerosos estudos. ${ }^{35}$ Apesar de seu estado fragmentá-

\footnotetext{
${ }^{30}$ Textos de Qumran, 219.

${ }^{31}$ Texto editado por F. García Marténez, E. Tigchelaar, A.S. van der Woude, Qumran Cave 11. II: 11Q2-18, 11Q20-31 (DJD 23; Oxford, 1998), 357-409, pl. XLI-XLVII; DSSSE 2: 1290-1304.

${ }^{32}$ Texto editado por E. Puech, Qumrân Grotte 4.XVIII: Textes Hébreux (4Q521-4Q528, 4Q5764Q579) (DJD 25; Oxford, 1998), 100. Ver seu estudo prévio, "Notes sur 11Q19 LXIV 6-13 et 4Q524 14,2-4. A propos de la crucifixion dans le Rouleau du Temple et dans le Judaïsme ancien," $\operatorname{RevQ} 18 / 69$ (1997): 109-124.

${ }^{33}$ Textos de Qumran, 237.

${ }^{34}$ J. M. Allegro, "Further Light in the History of the Qumran Sect," JBL 75 (1956): 89-95 y "More Unpublished Pieces of a Qumran Commentary on Nahum (4QpNah)," JJS 7 (1962): 304-
} 
rio $^{36}$, e do uso de apelido (como "leãozinho furioso", para designar a Alexandre Janeu e "buscadores de interpretações fáceis", para designar os Fariseus), algo que é comum e característico de todos os pesharim, este pesher de Naum é considerado como o manuscrito com as informações históricas mais precisas entre todos os achados em Qumran. No início da mesma coluna (4Q169 3-4 i 2-3), o texto de Na 2,12 é aplicado a "Demé[trio, rei de Javã, que quis entrar em Jerusalém por conselho dos que buscam interpretações fáceis [porém não entrou, porque Deus não entregou Jerusalém] na mão dos reis de Javã desde Antíoco até a aparição dos chefes dos Kittim." Este episódio, da história de Israel, nos foi dado a conhecer, com detalhes, por Flávio Josefo ${ }^{37}$, que nos relata como Demétrio III Eucário (94-88 a.C.) invadiu a Palestina durante o reinado de Alexandre Janeu, respondendo ao apelo do partido farisaico. O Rei Selêucida, ajudado pelas tropas rebeldes judaicas, impôs uma grande derrota a Alexandre Janeu em Siquém, porém, depois teve que se retirar, sem chegar a Jerusalém, já que foi abandonado pelos mesmos partidários. Flávio Josefo narra que Janeu, uma vez livre da ameaça de Demétrio III, derramou a sua ira contra os que o tinham chamado e crucificou cerca de 800 deles. Este é o feito refletido no pesher, que apenas citamos, no qual a crucifixão é designada como "dependurado vivo na árvore."

Este texto do pesher Naum prova, sem sombra de dúvidas, que a crucifixão já era praticada em ambientes judaicos antes da chegada dos romanos (designado no pesher por Kittim), e o texto do Rolo do Templo mostra que a interpretação de Dt 21,23 podia ser aplicada à crucifixão. Isto nos permite compreender o emprego paulino da citação: o maldito, pois, dependurado na árvore, é quem nos resgata da maldição da lei.

Poderíamos continuar com muitos outros exemplos contidos nos manuscritos do Mar Morto, que nos esclarecem sobre a linguagem empregada por Paulo. O uso que faz de "evangelho", "filhos da luz", "justiça de Deus", "mistério", "os pobres", "espírito de santidade", "carne de pecado" etc ${ }^{38}$. Todavia, é

308. A editio princeps foi feita pelo próprio Allegro, Qumran Cave 4. 1 (4Q158-4Q186) (DJD 5; Oxford, 1968), 37-42, pl. XII-XIV.

${ }^{35}$ As duas monografias mais recentes são as de G.L. Doudna, 4Q Pesher Nahum : A Critical Edition (JSPS 35; Sheffield, 2001) e de Sh. L. Berrin, The Pesher Nahum Scroll from Qumran: An Exegetical Study of 4Q169 (STDJ 53; Leiden, 2004), ambas com ampla bibliografia.

${ }^{36}$ As reconstruções, de minha tradução, fundamentam-se num estudo que publiquei há muitos anos, F. García Martínez, "4QpNah y la Crucifixión. Nueva hipótesis de reconstrucción de 4Q169 3-4 i 4-8," EstBib 38 (1979-80): 221-235. Texto hebraico em DSSSE 1: 334-340.

${ }^{37}$ Textos de Qumran, 236; Antiguidades Judaicas 13 \$377-381; Guerra Judaica 1§ 92-98.

${ }^{38}$ Vários dos usos de palavras em Paulo, que são iluminados pelos textos qumrânicos, são analisados no estudo de J. A. Fitzmyer, "Paul and the Dead Sea Scrolls," em P. W. Flint - J. C. VanderKam (eds.), The Dead Sea Scrolls after Fifty Years (Leiden, 1999) 2:599-621, e nas distintas publicações de H.-W. Kuhn sobre as distintas cartas paulinas à luz de Qumran. 
hora de apresentar, ao menos, um exemplo, em que os manuscritos de Qumran nos ajudam a compreender melhor a teologia do Apóstolo Paulo sobre o conceito da justificação pela graça.

\section{Justificação "somente pela graça"}

Poucos conceitos são tão característicos da teologia paulina como o da justificação pela graça. ${ }^{39}$ É sabido que, durante o período da reforma protestante, um dos elementos chaves, das disputas entre os católicos e os luteranos, era, precisamente, este conceito, cuja "descoberta" era atribuída ao Apóstolo, bem como a interpretação do valor judicial ou salvífico da justificação; uma disputa que, no mundo protestante, se concretizou na formula, solus Christus, sola fide, sola gratia ${ }^{40}$. Com a publicação dos manuscritos da Regra da Comunidade e dos Hinos da Gruta 1, viu-se, muito prontamente, que o conceito da sola gratia tinha precedentes no ambiente qumrânico ${ }^{41}$. Comparando o texto dos Hinos, que citaremos em continuação, com Rm 3,24, H.-W Kun dizia explicitamente:

"The קר ("only") of Hodayot XIII 16 is especially interest-
ing, because this is also what Paul means. In Romans 3:28, in
his German translation of the Greek New Testament, Martin
Luther added such an "alone" ("allein"), as opposed to the
Roman Catholic interpretation of his time, and now we find
this correct Pauline interpretation in Qumran! As far as I can
determine, apart from the polemic "not by faith alone" in
James 2,24, in all ancient Jewish and Christian literature this
is the only literary "only" concerning justification. Paul and,
in a negative way, James are speaking of justification by

\footnotetext{
${ }^{39}$ Ver, entre os numerosos estudos sobre o tema, P. Stuhlmacher, Die Gerechtigkeit Gottes bei Paulus (Göttingen, 1966) e K. Kertelge, "Rechtfertigung” bei Paulus. Studien zur Struktur und zum Bedeutungsgehalt des apulinischen Rechtfertigungsbegriffs (Münster, 1967) e as coleções de artigos editados por D. A. Carson et al., Justification adn Variegated Nomism. 1 The Complexities of Second Temple Judaism (WUNT. 2 Reihe 140; Tübingen, 2001), 2. The Paradoxes of Paul (WUNT. 2 Reihe 181; Tübingen, 2004).

${ }^{40}$ O. H. Pesch, Die Theologie der Rechtfertigun bei Martin Luther and Thomas von Aquin (Mains, 1967), 169.

${ }^{41}$ Entre os estudos específicos sobre o tema, ver os artigos de S. Schulz, "Zur Rechtfertigung aus Gnaden in Qumran und bei Paulus," ZThK 56 (1959): 155-185 e de O. Betz, "Rechtfertigung in Qumran," in J. Friedrich (ed.), Rechtfertigung. Festschrift E. Käsemann zum 70. Geburstag (Tübingen - Göttingen, 1976), 17-36 y el más reciente de E. Zurli, "La giustificazione 'solo per grazia' in 1QS X-9-XI e 1QHa ," RevQ 20/79 (2002) 445-477, así como las monografías de J. Becker, Das Heil Gottes: Hails und Sündenbegriffe in de Qumrantexten und im Neuen Testament (SUNT 3; Göttingen, 1964) e de E. Zurli, La giustificazione "solo per grazia" negli scritti di Qumran (Napoli, 2003).
} 
faith. So the sola gratia is Jewish, too, while the sola fide ("alone by faith"), of course, is specially Pauline". 42

Por "justificação" se entende, geralmente, a ação salvadora de Deus que, mediante sua justiça, declara ou faz o homem justo. Na carta aos Romanos 3,23-24, Paulo afirma: "visto que todos pecaram e todos estão privados da glória de Deus e são justificados, gratuitamente, por sua graça...", e em 3,28 "porquanto nós sustentamos que o homem é justificado pela fé, sem a prática da Lei." 43

O vocabulário semântico da "justiça" é expresso no Antigo Testamen-

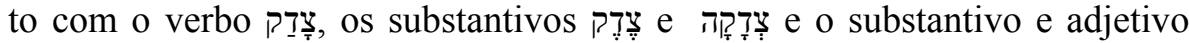
, Eִ de uma parte, e, de outra, com o campo semântico refere-se à "justiça", tanto no aspecto jurídico, como, no que poderíamos designar, salvífico. O campo semântico da "graça" está coberto

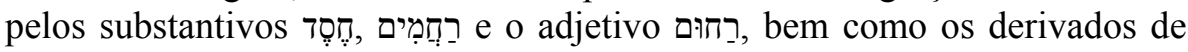

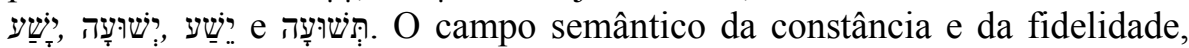

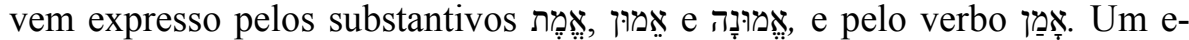
xame detalhado, das ocorrências destes termos ${ }^{44}$, permite concluir que, na Bíblia Hebraica, a concepção de justificação, enquanto ação salvífica de Deus com relação ao homem, somente se encontra de maneira implícita, enquanto que a misericórdia divina prevalece sobre o juízo (Ex 34,6-7). Em toda a Bíblia, porém, não encontramos uma afirmação explícita desta concepção. Nem sequer nos dois textos veterotestamentários, em que Paulo se apoiará para expressar sua concepção da justificação. Gn 15,6 é citado por Paulo em Rm 4,3 e em Gl 3,6, porém, com um significado distinto do que se encontra no texto hebraico. Este, traduzido literalmente, diz: "e colocou sua

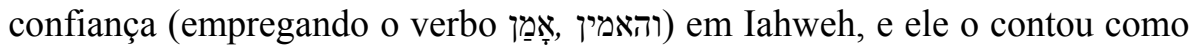
ato de justiça (צדקה)." Enquanto isso, o texto grego de Paulo, que segue a tradução dos LXX, (também citado em Tg 2,23), diz "Abraão acreditou ('Ê

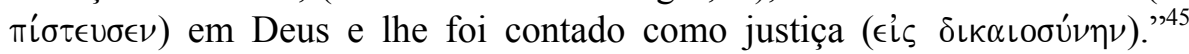

\footnotetext{
${ }^{42}$ H.-W. Kuhn, "The Impact of the Qumran Scrolls on the Understanding of Paul," 323-324.

${ }^{43} \mathrm{O}$ que, de modo algum, implica uma abolição da lei, visto que Paulo em 3,31 afirma: "Então eliminaremos a Lei através da fé? De modo algum! Pelo contrário, a consolidamos."

${ }^{44}$ Ver H. G. Reventlow, Rechtfertigung im Horizont des Alten Testaments (München, 1971) e M. A. Seifrid, "Righteousness Language in the Hebrew Scriptures and Early Judaism," in Justification and Variegated Nomism. I: 415-442.

${ }^{45}$ Ver os dois estudos de R. Mosis, “'Glauben' und 'Gerechtigkeit' - zu Gen 15,6," e "Gen 15,6 in Qumran und in der Septuagint," recogidos en su Gesammelte Aufsätze zum Alten Testament (Forschung zur Bibel 93; Würzburg, 1999), 55-93 y 95-118. As diferenças, entre a LXX e o TM, poderiam vir de outra forma de texto Hebraico, do que, agora, recuperamos parte em 4Q225, que conserva o primeiro verbo não no perfeito hifil mas como um futuro
} 
Para São Paulo, Abraão fora "justificado", quer dizer, salvo, pela sua fé em Deus, enquanto que o texto hebraico diz que, ter confiança em Deus é a forma de se comportar de quem é justo. O paralelo com o Sl 106,30-31, que emprega, exatamente, as mesmas expressões, falando de Finéias, é, totalmente, claro: "Mas surgiu Finéias e interveio, e deteve-se a praga; e lhe foi creditado como justiça, de geração em geração para sempre." O mesmo acontece com a citação de Hab 2,4 em Rm 1,17 e Gl 3,11, que examinaremos mais adiante, e onde se dá, também, a passagem de אֶ: $\pi$ a $\pi \tau \tau$, da fidelidade à fé, se ignora o contexto original do texto hebraico. E vai incluído o famoso texto de Is 53,11 , que é o texto mais próximo, como expressão, da idéia da justificação no Antigo Testamento (e ao que se alude, freqüentemente, tanto nos Evangelhos como nas cartas de Paulo), acredito que se possa traduzir, perfeitamente, por "meu servo justo fará justiça a muitos". Acredito, pois, que podemos concluir que a idéia paulina da justificação, pela sola gratia, ainda que esteja, claramente, enraizada na Bíblia Hebraica, não alcançou ali um pleno desenvolvimento.

A situação nos manuscritos de Qumran é muito distinta. Tanto na Regra da Comunidade, como, sobretudo, nos Hinos ou Hodayot, esta idéia já aparece formulada muito concretamente. Vejamos um texto da Regra ${ }^{46}$ :

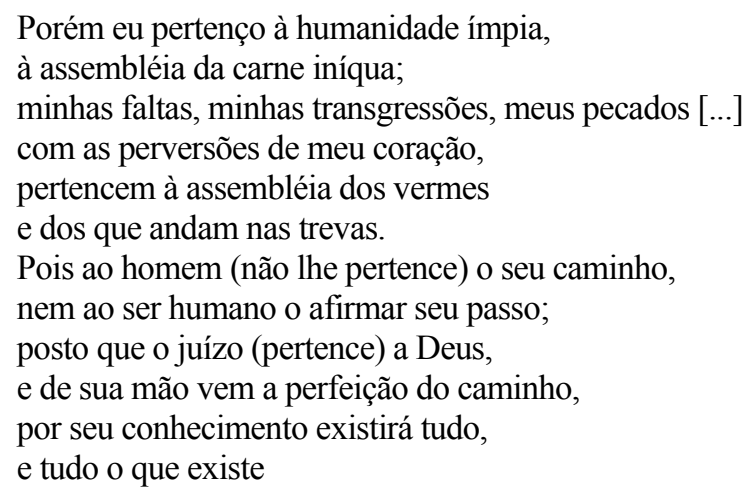

com waw e o segundo numa forma nifal, ver F. García Martínez, "The Sacrifice of Isaac in 4Q255," em E. Noort - E. Tighcelaar, The Sacrifice of Isaac (TBN 4; Leiden, 2002), 48.

${ }^{46}$ A editio princeps é a de M. Burrows em The Dead Sea Scrolls of St Mark's Monastery. Volume II. Fascicle 2: Plates and Transcription of the Manual of Discipline (New Haven, 1951) e tem sido reeditada muitas vezes. A edição mais cômoda é a de J.H. Charlesworth (ed.), The Dead Sea Scrolls: Rule of the Community. Photographic Multi-Language Edition (Philadelphia, 1996). A edição mais recente (que inclui em distintas cores todas as variantes dos manuscritos da Gruta 4) é a publicada como Apêndice ao livro de A. Schofield, From Qumran to the Yahad: A New Paradig of Textual Development for the Community Rule (STDJ 77; Leiden, 2009). O texto de base é a minha tradução em minha edição em DSSSE, I: 96-98. 


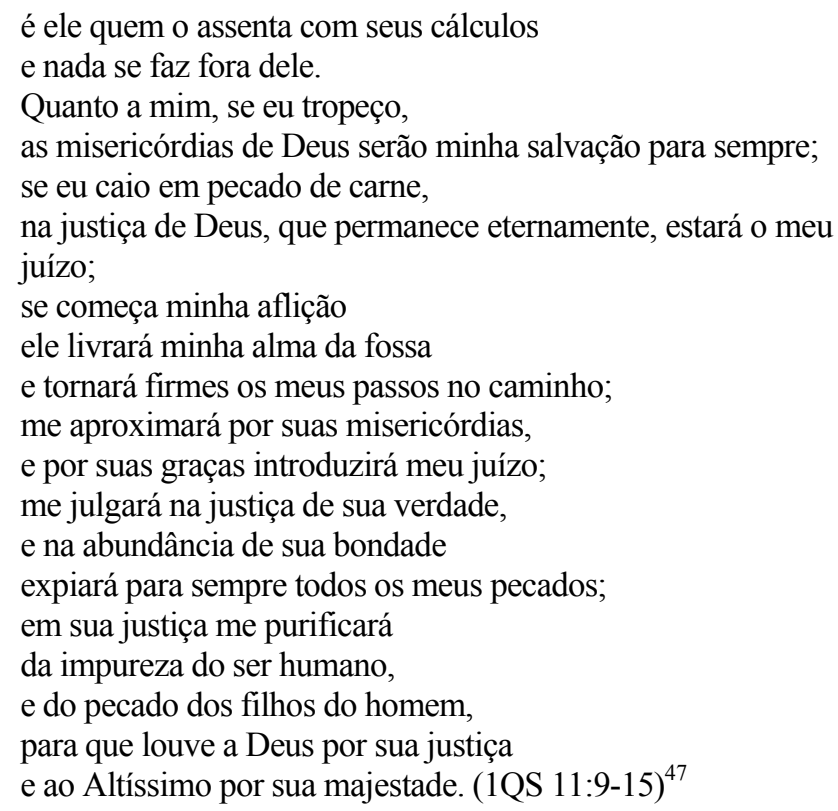

Neste poema, do qual citei somente uma pequena parte, o autor apresentou-se, previamente, não somente como um homem justo ("Quanto a mim, em Deus está o meu juízo; em sua mão está a perfeição de meu caminho com a retidão de meu coração e por suas justiças apaga o meu pecado" (11:2-3), mas como alguém a quem Deus revelou seus segredos ("Meus olhos contemplaram o que é para sempre, um saber que foi ocultado ao ser humano, conhecimento e compreensão (ocultados) aos filhos de homem, manancial de justiça e cisterna de poder e fonte de glória (ocultados) à assembléia de carne" (11:6-7), visto que é um dos eleitos por Deus para herdar a posse eterna no lote dos santos, e, junto com "os filhos dos céus", formar o conselho da comunidade e assim ser um dos "filhos da luz". Este mesmo autor, porém, se descreve, igualmente, como sendo, essencialmente, pecador e um "dos que caminham nas trevas". Nisto, ele é igual a todos os demais homens, e as primeiras linhas que lhes li não deixam alguma dúvida (11:9-10): é a natureza humana, enquanto tal, a que é essencialmente pecadora. É neste contexto que se situa a afirmação de que é a graça de Deus que salva de sua situação de pecado, que o purifica e o transforma, quer dizer, que o justifica. $\mathrm{O}$ autor expressa esta opinião, repetidamente, empregando todas as palavras e frases que, na Bíblia Hebraica, indicavam os campos semânticos da justiça, da graça e da salvação, porém, acentuando-

\footnotetext{
${ }^{47}$ Textos de Qumran, 60-61.
} 
as e dando-lhes um significado mais radical e forte. Também emprega expressões como que não se encontram na Bíblia Hebraica, mas que corres-

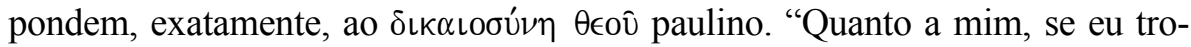
peço, as misericórdias de Deus serão minha salvação para sempre ( חסדי אל ישועתי); se eu caio em pecado de carne, na justiça de Deus, que permanece eternamente, estará meu juízo (משפטי בצדקת אל)", nos diz em 11:12. E em 11:14 e de modo, igualmente, claro: "e por suas graças introduzirá meu juízo (בחסדיו יביא משפטי), me julgará na justiça de sua verdade (בצדקת אמתו שפטני) e na abundância de sua bondade expiará (וברוב טובו יכפר) para sempre todos os

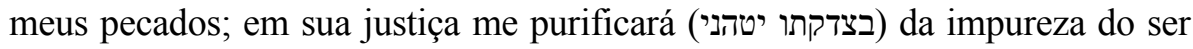
humano, e do pecado dos filhos do homem."

Nos Hinos ou Hodayot ${ }^{48}$ encontramos numerosas expressões que são semelhantes às da Regra, que provêm do mesmo contexto e transmitem a mesma concepção: é a graça divina, sua misericórdia, a que justifica o homem e o salva de sua condição de pecado. Cito, simplesmente, dois exemplos:

Quem é justo diante de ti quando é julgado?

Nenhum espírito/exército/ pode responder à tua repreensão,

Ninguém pode manter-se diante de tua ira.

A todos os filhos de tua verdade

/os levas/ ao perdão em tua presença,

os purificas de seus pecados

pela grandeza de tua bondade,

e na abundância de tua misericórdia,

para fazê-los estar na tua presença

por todo o sempre. $(1 \mathrm{QH} \text { XV 28-31 })^{49}$

Eu disse: "Por meu pecado fui excluído de tua aliança."

Porém quando recordei a força de tua mão

e a multidão de tuas misericórdias

me mantive firme e me ergui;

meu espírito se firmou em sua posição

frente à aflição.

\footnotetext{
${ }^{48}$ La editio princeps é a de E.L. Sukenik, The Dead Sea Scrolls of the Hebrew University (Jerusalem 1955), seguida por outras várias edições. Infelizmente, a ordem em que foram publicados os distintos hinos não corresponde aos dados do manuscrito, o que ocasionou uma grande confusão nas referências. Eu sigo a numeração de minha edição em DSSSE 1:146-205, que adota as conclusões do estudo de E. Peuch, Quelques aspects de la restauration du rouleau des Hymnes (1QH)," JJS 39 (1988):38-55. A pouco, foi publicada a edição de H. Stegemann e E. Schuller, Qumran Cave 1.III: 1QHodayot ${ }^{a}$ : With Incorporation of 4QHodayot ${ }^{a-f}$ and 1QHodayot $t^{b}$ (DJD 40; Oxford, 2008), que coincide com Puech na numeração das colunas, ainda que não na numeração das linhas de cada coluna.

${ }^{49}$ Textos de Qumran, 390.
} 
Pois me apoiei em tuas ternuras

E na abundância de tuas misericórdias.

Porque tu expias o pecado

e purifi[cas o homem] de sua culpa por tua justiça (1QH XII $35-37)^{50}$

A expressão mais forte e explícita da justificação pela sola gratia a encontramos, porém, no fragmento seguinte, que é o único (como já indiquei) ao especificar que é a sola gratia divina a que justifica o homem.

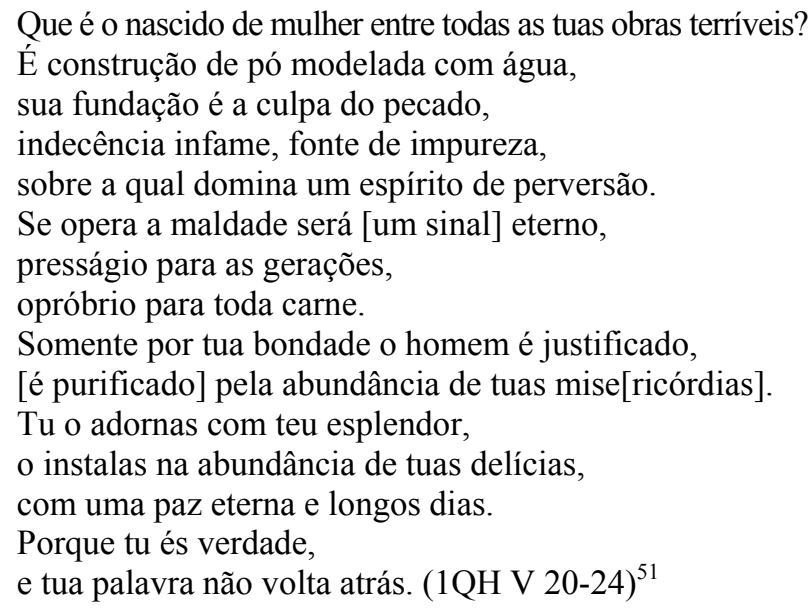

Como na Regra, o poeta insiste em dizer que o homem não é nada; como na Regra o autor emprega o vocabulário dos campos semânticos da justiça, da graça e da salvação, porém, à diferença da Regra, onde a exclusividade da graça em ação justificadora estava implícita, neste Hino, o autor a expressa claramente: "Somente por tua bondade o homem é justificado (רק בטובך יצדק אישר), [é purificado] pela abundância de tuas misericórdias (וברוב רחמיך יטהר)."

Não acredito que possam existir dúvidas, de que o desenvolvimento teológico, com relação ao Antigo Testamento, que Paulo expressa, freqüentemente, em língua grega, nas cartas aos Romanos e aos Gálatas, de que o homem pecador é justificado pela graça divina, tinha sido já realizado dentro do judaísmo pré-cristão e esteja atestado nos textos de Qumran. Paulo, porém, continua o texto no qual expressa sua concepção de "justificação pela graça" em Rm 3,2324 com a afirmação fundamental de que esta justificação, pela graça, se realiza

${ }^{50}$ Textos de Qumran, 382.

${ }^{51}$ Textos de Qumran, 366. 
"mediante a redenção por Cristo Jesus" $(3,24)$ e pela fé em Cristo, sem a qual ninguém é salvo: "Porquanto nós sustentamos que o homem é justificado pela fé, sem a prática da Lei" $(3,28)$, afirmações das que, por suposto, não existem algum traço nos escritos qumrânicos. Na formulação de Rm 5,1-2: "Tendo sido justificados pela fé, estamos em paz com Deus por nosso Senhor Jesus Cristo, por quem tivemos acesso, pela fé, a esta graça na qual estamos firmes..,52

Um texto interessante para compreender este desenvolvimento paulino, que, como estou dizendo, vai muito mais além dos desenvolvimentos já obtidos em Qumran, é a interpretação da citação de Hab 2,4b: וצדיק באמונתו יחיה justo viverá por sua fidelidade", que encontramos tanto em Paulo (Rm 1,17 e Gl 3,11 ), como no pesher de Habacuc da Gruta $1 .^{53}$ A citação do texto concreto de Hab 2,4b se perdeu ao final da coluna 7 do pesher, porém, sua interpretação foi conservada, plenamente, no início da coluna 8 :

Sua interpretação se refere a todos os que cumprem a Lei na Casa de Judá, aos quais livrará Deus do castigo por causa dos seus trabalhos e de sua fidelidade ao Mestre de Justiça. ${ }^{54}$

A primeira parte do texto de Hab 2,4 é problemática e de significado incerto, e tem sido, portanto, objeto das diversas formas de reconstrução ${ }^{55}$. Este, porém, não tem aqui demasiada importância, visto que é claro que o comentador (como fará, também, Paulo) separou a primeira parte do versículo da segunda e providenciou uma interpretação para cada uma das partes, desligando-as, assim, do contexto geral do texto bíblico. A interpretação que o pesher dá para a primeira parte é "que redobrarão sobre eles [a opressão e não acharão clemência] ao serem julgados." A este castigo, durante o juízo do pesher, da primeira parte

\footnotetext{
${ }^{52}$ Ver o estudo de W. Grundmann, "Der Lehrer der Gerechtigkeit von Qumran und die Frage nach der Glaubensgerechtigkeit in the Theologie des Apostels Paulus," RevQ 2/6 (1960): 237 259, traduzido para o inglês em "The Teacher of Roghteousness of Qumran and the Question of Justification by Faith in the Theology of the Apostle Paul," em Paul and Qumran, 85-114.

${ }^{53}$ A editio princeps é a de M. Burrows en The Dead Sea Scrolls of St Mark's Monastery. Volume I. The Isaiah Manuscript and the Habakkuk Commentary (New Haven, 1951). O texto foi reeditado com frequência. Eu sigo a edição de DSSSE I: 10-24. Entre os numerosos comentários, ver K. Elliger, Studien zum Habakuk-Kommentar vom Toten Meer (Tübingen, 1953); W.H. Brownlee, The Midras Pesher of Habakkuk (Missoula, 1979); M. Horgan, Pesharim: Qumran Interpretations of Biblical Books (Washington, 199), e B. Nitzan, Pesher Habakkuk: A Scroll from the Wildernes of Judaea (Jerusalem, 1986) (Hebrew).

${ }^{54}$ Textos de Qumran, 241.

${ }^{55}$ Ver P. J. M. Soutywell, “A Note on Habakkuk ii 4,” JTS 19 (1968): 614-617. Uma das traduções possíveis do TM, coincidindo com o texto qumrânico, seria: "Eis aqui, não teme em si a alma retamente disposta," ou, como eu traduzi: "eis aqui que se eleva, não se rende, sua alma nele," visto que as duas palavras empregadas são femininas e, ainda que a relação sintática com nefsho não seja clara, devem-se referir a alma.
} 
do versículo de Habacuc, se contrapõe, na interpretação da segunda parte, sobre a clemência para "os cumpridores da Lei na Casa de Judá", que são aqueles a quem Deus livrará ao final dos tempos. Os motivos desta libertação do castigo (literalmente, "da casa do juízo") podem ser interpretados diversamente. O que eu traduzi, "por causa de seus trabalhos" (בעבור עמלם), pode, igualmente, ser traduzido, "por causa de seus sofrimentos," que é um outro significado de 'amal; e o que eu traduzi por "fidelidade ao Mestre de Justiça", pode, igualmente, ser traduzido por "fé no Mestre de Justiça," visto que a palavra empregada está escrita de forma defectiva (ואמנתם), e pode ser vocalizada tanto como be 'emunatam (por sua fidelidade), como faz Lohse, ${ }^{56}$ como por ba'amanatam (por sua fé), como faz Habermann ${ }^{57}$. Em qualquer uma destas interpretações, podemos observar uma progressão com relação ao texto do Profeta Habacuc, visto que as palavras do profeta, reduzidas e separadas do seu contexto, já não se referem às circunstâncias que se referiam no oráculo do Profeta, senão que sua interpretação real mostra que estas palavras tratam da vida da comunidade, que já está vivendo "o fim dos tempos", e tem relação com a confiança ou a fé numa pessoa concreta, o Mestre da Justiça, a quem se referem as palavras dos Profetas. Por isso, é possível apresentar a história concreta da Comunidade de Qumran como a interpretação do significado profundo do texto sagrado ${ }^{58}$. O mesmo Pesher de Habacuc nos diz isso, expressamente, ao comentar o texto de Hab 1,5 :

\begin{abstract}
"A interpretação da citação [se refere aos trai]dores nos dias futuros. Eles serão violadores [da alian]ça que não crerão quando ouvirem tudo o que vai [acontecer à] geração futura da boca do Sacerdote que pôs Deus em [meio à comunidade] para predizer o cumprimento de todas as palavras de seus servos os profetas, [por] cujo meio anunciou Deus tudo o que vai acontecer ao seu povo [Israel]. (1QpHab II, 6-10)
\end{abstract}

A revelação divina, contida nos escritos dos Profetas ("tudo o que vai acontecer ao seu povo Israel"), não é outra coisa que "o que a geração futura vai passar". É, por isso, que toda a história da Comunidade pode ser lida dentro do texto bíblico, como sua real interpretação; é o que fazem os pesharim. E é, por

\footnotetext{
${ }^{56}$ E. Lohse, Die Texte aus Qumran (München, 1971), 236.

${ }_{57}^{57}$ A. M. Habermann, Megilloth Midbar Yehuda (Israel, 1959), 46

${ }^{58}$ Sobre esta maneira de interpretar o texto bíblico, característica dos pesharim, ver meu estudo "Escatologización de los escritos proféticos en Qumrán,” EstBíb 44 (1986): 101-116.

${ }^{59}$ Textos de Qumran, 239.
} 
isso, que os que cumpriram a Lei e se mantiveram fiéis ao Mestre da Justiça serão libertados do castigo e viverão.

A interpretação de Paulo é ainda mais radical e vai mais além da que é a dada pelo pesher. Emprega o $\pi \iota \sigma \tau \iota \varsigma$ da LXX, tirando, assim, toda a ambigüidade possível entre fidelidade e fé; suprime o pronome pessoal para fazer da fé uma proclamação absoluta: ${ }^{60}$ é a fé e não a fidelidade do justo a que fará viver (e não as "obras da lei"), e é a que dá, a este "viver", uma dimensão nova, visto que se trata de "viver em Cristo". No fundo, porém, Paulo realiza as mesmas duas ações operacionais que o autor do pesher realizou. As palavras de Habacuc já não possuem alguma relação com o contexto histórico ao qual, originalmente, se dirigiam, e podem ser utilizadas para expressar a situação presente da comunidade cristã, na qual a fé em Cristo é a fonte e a origem de toda a vida. Como o autor do pesher, Paulo separa a sua citação do contexto original. Como o autor do pesher, Paulo aplica o significado do texto à situação presente da comunidade, que está vivendo o "final dos tempos". Como o autor do pesher, Paulo refere estas palavras a uma pessoa concreta, Cristo Jesus, que constitui o centro de toda a sua teologia e interpretação das escrituras sagradas de Israel.

Acredito que fica claro, que as duas interpretações, tanto a qumrânica, como a paulina, sendo distintas como são e sem que haja alguma relação direta entre elas, as duas são um desenvolvimento das idéias já presentes, em semente, no texto bíblico. O que me leva a concluir, com algo que eu acredito que é a chave para compreender as relações existentes entre os textos qumrânicos e os textos paulinos (e mais geralmente entre os manuscritos do Mar Morto e o Novo Testamento, como falarei, com mais detalhes, na conferência final: Qumran e o Novo Testamento: Mitos e Realidades).

Os manuscritos de Qumran são essenciais para se compreender a mensagem paulina, e isto, não porque exista alguma relação de dependência direta entre uns e outros, entre Paulo e Qumran, senão porque ambos os grupos de escritos (as cartas autênticas de Paulo, sem levar em conta as possíveis interpolações, e os manuscritos do Mar Morto), desenvolvem, cada um a seu modo, e, freqüentemente, chegando a conclusões opostas, às idéias presentes em semente, porém não desenvolvidas, dentro de uma Escritura que é considerada autorizável e sagrada, tanto pelos autores dos manuscritos de Qumran, como por Paulo. Visto que, antes das descobertas de Qumran, os de-

\footnotetext{
${ }^{60}$ A LXX, que Paulo segue, neste caso, dá uma versão totalmente distinta da primeira parte do verso, e na segunda traz uma modificação essencial, mudando o pronome de terceira pessoa "sua" para a primeira pessoa "minha": באמונתו é traduzido por $\epsilon \kappa \pi\llcorner\sigma \tau \epsilon \omega$ ' cam o pronome num lugar diferente, "o justo viverá por minha fidelidade" ou "meu justo viverá pela fé”, porém, ninguém emprega o pronome de terceira pessoa do texto hebraico.
} 
senvolvimentos, que se lucram realizar no mundo judaico, eram-nos, totalmente, desconhecidos, não podíamos compreender muitas das coisas que o judeu Paulo exprime nas suas cartas escritas em Grego. Agora, com o acesso, ao menos em parte, da produção literária em que se plasmaram estes desenvolvimentos do texto sagrado, podemos comparar a interpretação que Paulo faz destes escritos sagrados, com a que está contida nos outros textos, o que nos mostra, de maneira evidente, tanto as semelhanças como as diferenças essenciais. Paulo é judeu, grego e romano, e, graças aos manuscritos de Qumran, podemos compreender melhor tanto o seu judaísmo como sua profunda originalidade, e, sobretudo, a fundamental novidade que consiste em fazer de Cristo Jesus o centro de sua teologia.

Os três temas, que comentei (obras da lei, a cruz como 'maldição' e a justificação pela graça), encontram-se reunidos na carta aos Gálatas 3,10-14. Um texto que nos mostra, igualmente, de maneira totalmente clara, como o pensamento teológico paulino se desenvolve através de sua reflexão sobre o texto bíblico, no que se refere às quatro citações, duas delas introduzidas, explicitamente, como tais: "pois está escrito." Este texto pode servir, perfeitamente, como conclusão e como resumo desta conferência:

"E os que são pelas obras da Lei, esses estão debaixo de maldição, pois está escrito: Maldito todo aquele que não se atém a todas as prescrições que estão no livro da Lei para serem praticadas (Dt 27,26). E que pela Lei ninguém se justifica diante de Deus é evidente, pos o justo viverá pela fé (Hab 2,4). Ora, a Lei não é pela fé, mas: quem pratica essas coisas por elas viverá (Lv 18,5). Cristo nos resgatou da maldição da Lei tornando-se maldição por nós, porque está escrito: Maldito todo aquele que é suspenso ao madeiro (Dt 21,23), a fim de que a bênção de Abraão em Cristo Jesus se estenda aos gentios, e para que, pela fé recebamos o espírito prometido." (Gl 3,10-14)

\begin{abstract}
This paper tries to present how the texts of Qumran can illuminate some elements of the St. Paul writings. Two examples, the language and the terminology, used by St. Paul, are analyzed and clarified by determined sentences of the manuscripts. From the level of the language, this study goes to the theological level of the Apostle, showing that it doesn't exist isolated from the language level, as St. Paul expresses its thought. As regard Paul's use of the Holy Writs, the common source, the Hebrew Bible, is the general
\end{abstract}


element which allows us to understand the relationship between the texts of Qumran and the New Testament, and, in particular, between Qumran and St. Paul, without the necessity of appealing to an improbable genetic relationship or to the literary dependence between the two writings.

Florentino García Martínez. K.U. Leuven was Professor of Early Judaism and Dead Sea Scrolls at the Catholic University of Leuven and at the University of Groningen where he led the Qumran Institute. He is a member of the International Team of Editors of the Dead Sea Scrolls, editorial secretary of the "Revue de Qumrân", and editor-inchief of the "Journal for the Study of Judaism". He has written numerous books and articles on the Dead Sea Scrolls. He edits the Series /Studies on the Texts of the Desert of Judah/, and / Supplements to the Journal for the Study of Judaism / (Brill) / and / Studies in the Dead Sea Scrolls and Related Literature/ (Eerdmans). 